\title{
THE PROBLEM OF THE TOTALITARIAN NATURE OF THE INFORMATION SOCIETY IN THE CONTEXT OF ITS INFLUENCE ON SOCIAL INSTITUTIONS
}

\author{
Vladislav Sheleketa ${ }^{1)}$, Vasilij Ivakhnov ${ }^{2)}$, \\ Irina Dmitrieva ${ }^{3)}$, Natalia Revenko ${ }^{4}$ ) \\ 1)Belgorod State Technological University (Russia) \\ ${ }^{2)}$ Volgograd State Technical University (Russia) \\ ${ }^{3)}$ Plekhanov Russian University of Economics (Russia) \\ ${ }^{4)}$ Belgorod University of Cooperation, Economics and Law (Russia)
}

\begin{abstract}
The article discusses the features of the process of transformation of human consciousness and educational culture in the conditions of the modern information society in the context of digitalization. By using such concepts, the theory of postmodernism and existentialism, the authors prove the legitimacy of the explication of these theories on the processes of transformation of human consciousness and radical changes in educational culture. At the same time, the necessity of critical reflection on the processes and phenomena from the perspective of the basic values of human life, such as love, moral values, creativity, is emphasized. The role of independent and systemic thinking as a condition for selfrealization is also proved.

The phenomenology of modern consciousness, intertwined with the phenomena of technology, is the basis of the existential analysis of consciousness. According to the authors, it is an utmost technological and utilitarian orientation of consciousness. Consciousness today is a reflection of the technological orientation of society and this cannot but affect the educational culture, which is becoming technological. The information space modulates the independence of thinking as a support for authoritative opinions, awakening the needs for material well-being, to the detriment of the dialogic nature of thinking and the independence of thinking.

Keywords: information society; social Institute; transformation of consciousness; simulacra; technique; manipulation
\end{abstract}

\section{Introduction}

The problem of the formation of human consciousness by social institutions is actualized in the era of the formation of a total information society, the prerequisites 
of which we observe today. This type of society can combine the characteristics of totalitarian and utopian societies with the realities of information technology. Hyperrealism and total technologization of all aspects of human life are the main parametric characteristics of such a society. This is a society of total information control. ${ }^{1)}$

On the other hand, the transition to the information society, the processes of international integration and globalization in science leads to an increasing role of education in the modern changing world with modernization processes that affect all aspects of social reality. The problems of education and educational culture, their present and future become very relevant. A very important social reality that determines the relevance of raising the issue of educational culture is the total informatization of society as a phenomenon of the information age, especially in the context of the modernization of education. The key issue for preserving education as a system of the individual's involvement in the universal culture is, according to our opinion, the formation of his ability to pose global problems. The knowledge within which the formulation is carried out and the subsequent resolution of these issues we suppose to be philosophical knowledge. An important integrative value of philosophical knowledge is that it is within its framework that the synthesis of knowledge supplied by various sciences takes place, which means that the main task of education is realized as the formation of the student's adequate scientific picture of the world.

\section{The problem of control society and the methodology of structuralism M. Foucault}

The problem of control society has been troubled by liberal-minded minds since the time of the emergence of political science thought and the time of understanding the stages of the existence of empires and totalitarian imperial dictatorships. Today however during the actual disintegration of global associations built, for example,of the European Union, of a new liberal type, and the creation of a new geopolitical space, the understanding of the realities and prospects of a new type of society is placed on the plane of general theoretical discussions where the philosophical such as an extremely universal explanation can say its weight word.

The emergence and development of the information society raises the question of the possibility of definitions and discussion of the phenomenon of "culture of the information society". In connection with the development of the media as a special type and space of culture, with its specific products of this type of culture, the problem of localization and determination of manifestations of cultural discourses of the information society arises. In our opinion, the structural methodology of M. Foucault, the methodological approaches of postmodernism and poststructuralism are quite applicable today to the analysis of socio-cultural phenomena. Thus, modern society can be defined as "superdisciplinary" or 
"postdisciplinary", that is, discipline as the concept of structuralism of M. Foucault (Baudrillard, 2018: 224) is brought to its maximum within its limits, due to the distribution of various kinds of measuring and control tools that form disciplinary practices. The concept of "simulative" from the theory of J. Baudrillard (Baudrillard, 2018: 216) is quite applicable to the characterization of the information society, in which culture acquires all the signs inherent in hyperreality and cultural simulations.

Strengthening power in modern culture is no longer discreetly and gradually, through the use of mechanisms for structuring social practices, but through the regulation of cultural discourses.

The production of spiritual values ceases to be the prerogative of the spiritual elite and intelligentsia, removes these values from its sphere of responsibility which leads to the loss of significance of the issue of the spiritual state of society and communication between the people and the elite. Such a gap leads to the loss of the value of old ties and traditional communities and the formation of new which are formed on different principles.

Moreover, this applies to educational culture.

In modern sociocultural conditions, despite the tremendous successes of civilization, creating the comfort of life and huge potential for development, the crisis in the educational culture is evident, and it is gaining momentum. This is expressed in a sharp discrepancy between the stated goals and objectives with the real state of affairs in education, in catastrophic forms of its financing. Education and life exist on different planes, and carry opposing trends. The reforms carried out in the field of education did not bring the proper result, the existing goals, content and forms of education became ineffective. On this account, L. Bugaeva notes: "The democratization and humanization as fundamental principles of education reform in Russia are difficult to reconcile with the contradictions of the real situation, both in education and in the country as a whole" (Bugaeva, 1999: 14)

Modern education in Russia is not connected with upbringing, with instilling cultural values and moral standards, knowledge is perceived as a commodity. Utilitarian values come to the fore, imitation dominates and there is no independent creative principle. Higher education is becoming more practical, and educational and cultural tasks are sacrificed to a utilitarily understood learning function. But it is the educational culture of society that determines the motivational sphere of human activity, the focus is of all social transformations. Already in ancient times, thinkers considered education as a condition for the formation of a person, his movement towards an ideal being. Modern educational culture has lost its old spiritual and moral guidelines, without forming new ones. This is largely due to the fact that the systemic worldview is losing its leading role in the higher education system, philosophical knowledge is relegated to the background, and private sciences 
are preferred, giving only a fragmented perception of reality that narrows human thinking.

A little more about relevance we can add.

\section{Educational culture and theory of simulacra J. Baudrillard}

The prospects for the development of a new type of society appeared more clearly in the picture of our political, cultural, social and economic in connection with the so-called pandemic of the coronavirus. Thus, the economic consequences of this global epidemic have manifested themselves in the backwardness of "resourceoriented economies" in comparison with high-tech and "technology-oriented" ones. In this regard, a more intensive development of new industries is expected the information, synthesis of information and biological technologies, pharmaceutical industries, which in general should be aimed at creating a material and production basis for going beyond the limits of the dependence of society and the economy on nature, its resources. Thus, the blow to the oil dependence of many countries actualizes the development of technologies that have existed for a long time in a latent state, since they were disadvantageous to oligarchic groups speculating on non-renewable hydrocarbons.

In the educational system, an impetus has been given to the development of various types of distance learning technologies. At the same time, the thoughtless use of these technologies in the educational space creates two opposite ways of developing the educational process; on the one hand, educational technologies expand the possibilities for a person to receive information and today there are various forms for obtaining information, and it is also becoming more accessible. On the other hand, the introduction of distance learning courses, video lectures, due to the characteristics of the human psyche (as he cannot perceive information alone for a long time), the direct connection between the teacher and the student is lost, ensuring continuity and interest in the assimilation of information, the perception feedback mode is interrupted and the control is over the assimilation of information. Moreover, in the process of watching a video lecture, the listener does not have the opportunity to ask inevitably arising questions. Even if the possibility of feedback is provided, for example, the question can be recorded and sent, the emotional outburst akin to philosophical surprise subsides and the interest in sending the question disappears. A parallel that can serve as an example is the phenomenon of social networks, where individuality is lost behind the illusory nature and unreality of the picture created in the information space.

The problems arising from the thoughtless use of technology are interpreted today in psychological and philosophical discourses, and philosophers conclude that such use leads to depersonalization of people and also to distancing people from each other, the phenomenon of public loneliness and abandonment. The fundamental categories of existentialism appear today in a new and very visual way. 
The advantages of bodily and personal live communication have undeniable advantages over virtual (the most obvious example is dating and communication on the Internet, where the most illusory space is created in the form of protruding certain beneficial features and retouching disadvantageous ones). An indicator of the crisis of this social institution is the statistics of the breakdown of families due to the lack of ability to live together, the ability to manifest their highest moral qualities, ability to tolerance, love, etc.

All this, in our opinion, is a global simulation and imitation of all aspects of human life. Here, according to our opinion, the theory of simulacres by J. Baudrillard is quite adequate.

He identifies three orders of simulacra:

- simulacra natural, naturalistic, based on the image of imitation and fake, harmonious optimistic and aimed at restitution or the ideal institution of nature in the image and likeness of God;

- productive simulacra aimed at increasing productivity based on energy, the strength of its material embodiment in the machine and the entire production system, - Promethean desire for globalization and continuous expansion, for the release of unlimited energy, this desire is part of the utopias associated with this order of simulators);

- simulations based on information modeling of a cybernetic game - complete operationalism, hyper-realism aimed at total control (Baudrillard, 2018: 216).

Today we are obviously dealing with third-order simulacra. This is really what Baudrillard calls "hyper-realism"; it is the expression of a new, technologically hypertrophied reality, characterized by a higher degree of functionality, materialism, the embodiment of fantastic utopias, where all aspects of human life are extremely interconnected. At the same time, this interconnectedness in the information space and interrelation in each other, of course, facilitates total control over these aspects of individual and social life.

Analyzing the work "The Car Crash" as an example of science fiction, which can already be quite legally extrapolated to reality, he writes: “... this is our world, nothing is invented in it, everything is hyperfunctional in it, traffic and accident, technology and death, sex and a photo lens. it all seems to be some kind of large, synchronous and simulated machine, that is, the acceleration of our own models, all models that surround us mixed and hyper-operationalized in the void " (Baudrillard, 2018: 225). Unfortunately, all the terms used by Baudrillard denoting an extremely technologically advanced reality, which is the maximum manifestation of simulation called "simulacra", accurately reflects the current realities, the actual quasi-reality of our everyday life, as well as social institutions - education, marriage, etc.

At the same time, J. Baudrillard builds his concept of simulacra precisely on the thesis of mixing discourses, total indistinguishability and destructuring of all distinctive principles in society, which, in essence, is based on the interchange 
of information of various levels of culture and communicative flows. So, he writes that "it has never been so obvious that the content, in this case culture, and in others, information or commodities which acts only as a ghostly support for the action of the medium itself whose function has always been to induce mass, to create a homogeneous human and mental flow" (Baudrillard, 2018: 125). Considering the phenomenon of the "Museum of the Cultural Achievements of Bobur" in France, in which the achievements of mass culture, despite their mass character, are combined with the achievements of elite culture, Baudrillard describes them as a crazy eclectic collection of "simulated" formations of the information society since "in this building (Bobur Museum) there is an accumulation in one homogeneous space - time of all disparate functions of the social body and life (such as leisure work, media culture)..." (Baudrillard, 2018: 125). This construction and the phenomenon of mass culture as a whole replicates modern society with all its social subsystems.

This is the phenomenology of modern consciousness interwoven with the phenomena of technological effectiveness. Consciousness today is a reflection of the technological orientation of society, the total nature of information technology or the totally but variably constructed information. The awareness of the authorities about the individual exceeds all the limits allowed by the previous stages of the development of culture which makes the information society totally informational, where totality is quite successfully transformed into totalitarianism.

All this is reflected in the human consciousness, it becomes clichéd, perceiving the world excessively systemically, according to the schemes in accordance with which artificial information systems work. In turn, the human consciousness loses its specific characteristics - creativity and criticality, and the level of moral foundations naturally decreases. N. Berdyaev wrote about this when he comprehended the phenomenon of creativity as a fundamental characteristic of human being and consciousness, anticipating the problems of modern technogenic civilization. Technique ceases which are used to be neutral are no longer neutral, not indifferent to the spirit and issues of the spirit. And nothing in the end is maybe neutral something could seem only until a certain time and only on a superficial look. Technique has a killer effect on the soul, but at the same time it provokes a strong reaction of the spirit. left to itself, turned out to be weak and defenseless against the growing power of technology, then the spirit can turn out to be strong enough (Berdyaev, 1933: 24).

\section{Existential Analysis of Social Institutions}

The changing perception which acquires a technological format negatively affects the human psyche. The excess fragmentation of the mosse-like nature of information impedes a person's ability to adequately reflect the world and opportunities for spiritual growth. Because these abilities suggest the variability 
of thinking, which is lost in the conditions of technocratic culture, including a culture of thinking. With the development of artificial intelligent systems, the true reality of being as such is being replaced by existentialism (Heidegger, 1993: 221). Technique as "setting obscures being from a person", "deprives a person of living space, makes his existence illusory. To denote the technological ontological artificiality, Heidegger uses the word "By becoming" which collects the beginning of the attitude that sets, that is, forces a person to deduce the real from his secretiveness by setting him as an all-in-one. By extension is called that method of disclosing the secret that rules the essence of modern technology, without being anything technical. Everything that is familiar to us in the form of all kinds of machines, mills, plants and serving as an integral part of what is called production refers to the technical. The latter, together with all its constituent parts, relates to the field of technical manipulation, which always only meets the requirements of the post, never forming it and not even affecting it (Heidegger, 1993: 225). The existential analysis of technology, according to Heidegger, reveals to us the deep secretiveness of the essence of technology. But, in our opinion, the truthfulness of the being of technology, from an existential plane, logically leads us to the concept of illusory.

Illusoryness becomes the total characteristic of being. So, for example, the modern banking system gives a person an illusory impression that he has broad financial capabilities, which leads to an inadequate and disproportionate increase in his lower utilitarian needs. This is the mechanism for monitoring and regulating human behavior in society by programming its consciousness and behavior. This is a manifestation of just the technological manipulative way of regulating behavior. Interestingly, in this situation of authenticity, it is difficult for a person to meet even with himself. Heidegger writes: "Meanwhile, in fact with his being, man today just nowhere to be found. A man is so decisively drawn into the position that he does not perceive it as a challenge to him, he sees himself as being captured by this challenge, thereby listening to all the ways in which he captures himself from his being, and therefore can never to meet among the objects of his presentation just himself (Heidegger, 1993: 223).

False needs, formed by modern socio-economic institutions, form a feeling of well-being in a person, while the existential torment of creativity, conscience, choice is fading into the background of consciousness. Life-meaning issues, goalsetting are replaced by the achievement of momentary goals. The pursuit of truth also goes to the secondary plans of human interests, because production as being simulated by the simulacra of modernity is, in accordance with the existentials of man, concealing the truth about the world. In this way, the supplying industry not only conceals the old way of revealing the secret, the work, but also hides, and the disclosure of the hidden as such, and with it what the event of going out of the secret is, is the Truth (Heidegger, 1993: 228). 
The modern information culture is formed as an illusion, which, in turn, forms a utilitarian-pragmatic attitude to various spheres of interhuman interactions. Accessibility of social benefits is inspired to man, moreover "here and now". The absolutization of a pragmatic approach to life leads to the illusion of a person that everything in this world has a price, the money is an equivalent of love and friendship, any interpersonal relationship, the possibility of atonement for sin. In a certain sense, this is a renaissance of a medieval worldview, when it was possible to atone for any sinful act with the purchase of indulgences. An example is the huge number of divorces after the first year of life when the illusions formed in the human mind with the help of the mass media, about the essence of love, family and other spaces for the manifestation of existential "openness" collapse and love loses its moral foundation as the most important existential existence of a person. The consumer culture generated by technogenic civilization forms the vector of "to have or use" as an expression of the world of "material" culture to the detriment of the personal, deep-seated vector based on the disclosure of personalities "to each other". This is an egoistic obsession with oneself when an individuality hypertrophied by needs which prevents the opening, to the detriment of the individual.

Today we live in a time of intellectual crisis, when the sophistic method of "doubting everything" is supported by the contradictory and contradictory nature of information. The truth about the world in the post-structuralist world is not just conventional and objective-it becomes, in the language of J. Bondrillard, "implosive", blurring. Socrates 'phrase' know yourself' loses its true meaning, as the "I "is blurred on the surface of existence, degenerating into a set of psychological characteristics, losing the" depth" of the innermost personal. Dialogic consciousness instead of uncritical assimilation of postulated patterns and ideas-this is the way to awaken self-thinking consciousness.

Beyond the boundaries of the Dialogic space, there can be no true development of thought. The purpose of the dialogue is to develop rational strategies of behavior and activity, it acts as a way of self-knowledge, self-development and formation of a creative personality. "Dialogue is a way for individuals to clarify and understand the ideas of the common good in order to ensure joint conditions for self-realization" (Biryukova, 2000: 27). Cultivating a philosophical dialogue in the educational environment, provides self-improvement and self-realization of a person, contributes to the improvement of the educational culture of society. "The educational culture of society is an objective qualitative indicator of the subjects of social activity of the individual, society, and the state and expresses the nature and level of social activity of people. In this context, educational culture is considered not just as an indicator of the level of education of the country's population, but as one of the important indicators of the development of society at a particular historical stage" (Radugina, 2011: 141). 
The restoration of the status of philosophical knowledge in the system of higher education, the active use of forms of philosophizing in the educational environment are necessary means for the development and improvement of not only the educational culture of society, but also the culture of the individual. "Philosophy acts as an integrative component of the integrated education and the process of socialization of the individual. It also acts as a system-forming component of a person's personality, since it is universal knowledge" (Sheleketa, 2020: 176).

Dialogicism is the essence, the deep specificity of human culture itself as a phenomenon of human being. In this sense, philosophy as the core of culture is a form of the person's realization in the world, because dialogicity is also a dialogue with oneself in the space of which a person poses and answers fundamental lifemeaning questions: what is the meaning of life in general and of my being in particular, what life is, why there is death, and, ultimately, what is a human being. Education in this context can be considered as a continuous process of forming one's worldview, as well as raising the level of culture, since a civilized person, even with an education, is not yet an intelligent person.

\section{Conclusion}

Summarizing the foregoing, it can be argued that in the modern information space, in the context of introducing new educational methods that are of a technological nature, it is necessary to provide conditions for the development of independent thinking skills for the formation of deep existential modes of human being.

\section{NOTES}

1. The article was implemented in accordance with the program of the "Strategic development of the BSTU named after VG Shukhov for 2017 - 2021"

\section{REFERENCES}

Bugaeva, L. (1999). The crisis of education and problems of the philosophy of education. Questions of philosophy, 3, $12-19$.

Baudrillard, J. (2018). Simulacra and simulation. Moscow: Postum.

Berdyaev, N. (1933). Man and machine. The problem of sociology and metaphysics of technology. Way, 38, 3-37.

Heidegger, M. (1993). Question about technology (pp. 221 -238). In: Time and being. Moscow: Republic.

Biryukova, G. (2000) Dialogue: socially - philosophical analysis: Abstract of thesis of Dr. Philos. Sciences. Ivanovo.

Radugina, O. (2011). The educational culture of society as a holistic social phenomenon. Philosophy and society, 1, 130-141. 
Sheleketa, V. \& Kazintseva, N. \& Ivakhnov, V. \& Zagovenyeva, V. (2020). Philosophy as an integrative component of educational culture in the situation of the information society: socio-psychological aspects. Filosofiya-Philosophy, 2 (29), $174-183$.

\section{Prof. Dr. Vladislav Sheleketa}

ORCID iD: 0000-0002-4515-4420

Department of Theory and Methodology of Science Belgorod State Technological University V. G. Shoukhov Belgorod, Russia E-mail: vladshelo@mail.ru

Dr. Vasilij Ivakhnov, Assoc. Prof. ORCID iD 0000-0003-4786-5733

Department "Social and Humanitarian Disciplines" Volzhsky Polytechnic Institute Volgograd State Technical University Volgograd region, Russia E-mail: vasilij-ivakhnov@yandex.ru

$\checkmark$ Dr. Irina Dmitrieva, Assoc. Prof. ORCID iD: 0000-0003-0291-0369

Department of Management and Commerce Volgograd branch of Plekhanov Russian University of Economics Volgograd, Russia E-mail: dmira@mail.ru

$\triangle$ Dr. Natalia Revenko, Assoc. Prof. ORCID iD: 0000-0003-3697-3368

Department of Humanities and Social Sciences and Legal Disciplines Belgorod University of Cooperation, Economics and Law

Belgorod, Russia E-mail: nat555rev@yandex.ru 